\title{
KEYWORD INDEX TO VOLUME 2
}

adolescence, 210

Anzaldúa, 304

Aztlán, 304

California, 186, 210

Chicago, 26

Chicano, 304

citizenship, 4, 26, 70, 90, 140, 160

Colombia, 45

commodification, 395

community organizing, 186

criminal alien enforcement, 328

critical legal studies, 26

cultural citizenship, 186

democratization, 4

deportability, 160

discourse, 90

Dominicans, 90

dual citizenship, 45

education, 210

Esmeralda Santiago, 377

feminism, 304

gender, 186

globalization, 4

Great Lakes History, 352

Illegal Immigration Reform and Immigrant

Responsibility Act (IIRIRA), 328

illegality, 160

immigration, 90

immigration law, 160

Latinidad, 304

Latinos, 4, 395

Latino culture, 377

legal studies, 70

legislative politics, 210
Mexican American History, 352

migration, 45, 70

multiculturalism, 395

naturalization, 45

New York City, 90

New York City history, 140

New York City politics, 140

political anthropology, 70

political community, 4

political culture, 70

political participation, 45

popular education, 26

Proposition 187, 210

Puerto Rican culture, 377

Puerto Rican women, 377

Puerto Ricans, 26, 140

race, 160

racialization, 186

racism, 395

recreation, 352

regionalism, 4

removals/deportations, 328

sports, 352

sports Associations, 352

tourism, 395

transnational, 304

transnational organization, 45

transnationalism, 70

underprivilege, 395

undocumented Mexican migration, 160

undocumented migration, 210

urban, 395

welfare reform, 90 